\title{
Evaluation of Indoor Residual Household Spraying (IRHS): Challenges Faced by Ndola Urban District
}

\author{
Article by Vivian mwiinga \\ Publica Health, Texila American University \\ E-mail:v.mwiinga@yahoo.com
}

\begin{abstract}
The study aimed at determining challenges associated with implementation of IRHS in Ndola urban district, Zambia.

Method: A cross section study conducted at Ndola city council over a period of six weeks, all 122 expert service providers were purposively selected, between October and November 2008. Semistructured questionnaires and checklist used. Data analyzed by content analysis, Univariate and bivariate analysis, SPSS version 11.5. Chi-square determined association of variables; adherence, availability of logistic, acceptability of IRS and the outcome IRS challenges.

Results: Policy challenges: There was compliance $n=7$ with storage and disposal guidelines, while $n=4$ did not comply with use and environmental safeguards, as Spray operators spilled DDT on the ground.

Operational challenges: $81.3 \%$ of the respondents said experienced no problems while, $71.4 \%$ experienced itching, sneezing, and difficulty breathing, $p$ value 0.005. 66\% of Spray operators reported fewer problems implementing IRS while, 12\% said had poor training and acquired less skill, $p$ value $0.017 .75 .2 \%$ revealed that Acceptability of IRS was low and $24.7 \%$ said IRS was not effective $p$ value 0.036 validated by $n=7$ program officers. $28.1 \%$ reported repainting of walls, $44.7 \%$ reported variations in spraying due to late arrival of logistics $68.4 \%$.

Institutional challenges; $43.9 \%$ reported inadequate shower and wash bay facilities and affected their operations much $n=4$. A checklist revealed serious inadequacies evident in poor transport, disposal bay, preparation bay, wash bay, and change rooms.

Conclusion: Poor institutional structure, insufficient logistics greatly impinged on daily operations of IRS and highly contributed to non-adherence to some policy guidelines.
\end{abstract}

Keywords: Indoor Residual Household spraying.

\section{Introduction}

\section{Background information}

The burden of malaria is unacceptably high globally. Today malaria remains a major cause of poverty and underdevelopment, and it is estimated that 3.2 billion people live at continuous risk of this disease. Each year, there are more than 350 million cases of malaria and more than a million deaths from the disease. More than two-thirds of malaria cases occur in Africa, as well as approximately $90 \%$ of deaths, which are mainly in children under five years of age (WHO 2006) and part of the answer rests with IRHS.

Its importance as a public health problem is reflected by the staggering toll malaria extracts in illness and suffering. In general, malaria epidemiology has the characteristics of a stable, endemic infectious disease. Consequently, at a macro-epidemiologic level, malaria is not as much an emerging disease as it is an established, intractable public health plague for fully one-third of the earth's population (Olliaro, 1996: WHO, 1994).

WHO defines IRHS as the application of liquid insecticide with long-lasting residue properties which dries to form a crystalline deposit on the sprayed surface; the mosquitoes that come into contact with the surfaces absorb a lethal dose of the insecticide. Reducing the lifespan / longevity of the adult anopheles mosquito and reducing the density of adult anopheles mosquitoes (NMCC 2005). IRS can kill a mosquito any time it enters a house for a blood meal, which it typically does every 2-3 days, so that few will survive the approximately 12 days that are required for malaria parasites to complete part 
of their life cycle in the vector mosquito, if all the houses they visit are properly sprayed. IRS is a method for community protection, and given its mode of action, the highest possible level of coverage is required to achieve the maximum impact on malaria transmission. Achieving this level of coverage and timing spraying correctly (in a short period of time before the onset of the transmission season) are crucial to realize the full potential of IRS (WHO 2006).

In the last 20 years Africa has witnessed a shift in strategic emphasis away from the unattainable eradication of malaria towards the reduction and effective management of disease outcome (Dobson 1999). Roll back malaria (RBM) was launched in 1998 and was built on the technical elements of the global strategy for malaria control (WHO 2000). Central to renewed efforts to Roll-Back Malaria (RBM) is the reduction of mortality through use of Indoor residual spraying (WHO 2000a). Scientific evidence of IRS efficacy in reducing or interrupting malaria transmission in different epidemiological settings has been available since the 1940s and 1950s (De Mellion 1936; Russell 1955). The first house spraying campaigns, just after World War II showed the capacity of this intervention to produce profound reduction in malaria transmission due to reduction in malaria vector longevity (Hanson $\mathrm{K}$ et al 2004). Numerous studies have shown that IRS has substantially reduced infant and child mortality. This evidence formed the rationale for introduction of IRS as a primary intervention for malaria control and eradication. Despite its initial widespread use and contribution to the success of malaria eradication and control efforts, in recent years, the use of IRS has declined. This is due in part to lack of government commitment and financing to sustain these efforts over the long term and to concerns about insecticide resistance and community acceptance (WHO 2006). However, another important factor has been general disapproval of DDT use, due to fears of its harmful effects on the environment and on human health, fears which are unjustified when DDT is used appropriately for IRS (Govere 2004).

While this seems to be an apparently simple strategy, the majority of the African continent has a number of distinguishing features which make this approach complex. Hence the need to explore the problems associated with IRS.

In Zambia, Malaria currently accounts for nearly four million clinically diagnosed cases per year, $36 \%$ of hospitalisations and outpatient department visits, and about $20 \%$ of maternal mortality (NMCC strategic plan 2006- 2011). To address the disease burden of malaria, indoor residual household spraying (IRHS) is one of the primary malaria prevention strategies in Zambia and is carried out in 15 districts targeting urban and peri-urban areas in 2007. These include Kazungula, Livingstone and Mazabuka in southern province; Solwezi in north western province; Chongwe, Kafue and Lusaka in Lusaka province; Chingola, Kalulushi, Chililabombwe, Kitwe, Luanshya, Mufulira, and Ndola in copperbelt province; Kabwe in central province. It has expanded from two districts in 2000, to five districts in 2003, then to fifteen (15) districts in 2006/2007 and now to thirty-six districts in 2008/2009. The main objective of IRS work area for 2007 was to increase coverage among eligible populations from $75 \%$ to $85 \%$ by 2008 (approximately 700,000 households in 15 districts) and to be maintained to $100 \%$ by 2011 . Planned activities among others included prioritizing adherence to environmental monitoring and safeguards, strengthening logistics and availability of transport, storage facilities to conform to environmental council of Zambia (ECZ), he rapid scale-up of IRS coverage from $75 \%$ to $85 \%$ in 2008 and to be maintained to $100 \%$ in 2011 can only prove successful if communities accept IRS. However, there are challenges that are inhibiting the country from meeting this target.

\section{Statement of the problem}

In Zambia malaria is still the number one cause of morbidity and mortality among the top 10 killer diseases, with an incidence of 412/ 1000 (MOH, HMIS 2006). It accounts for $45 \%$ of all out patient attendances and $50 \%$ of admission cases among children under-five years of age (MOH, HMIS 2004). It also contributes to about $20 \%$ of maternal mortality and $40 \%$ of infant and under-five child mortality (NMCC 2005). To reduce the disease burden integrated vector management has been introduced, of which IRHS is one of the interventions. Studies have shown that IRHS with DDT reduced annual malaria prevalence from $74 \%$ to less than $1 \%$ in 1979 over a 2year period in konkola copper mine in Zambia (Tren \& Bate 2004). In Copperbelt province 180 villages were sprayed with insecticide in 
1979 and parasite rate ranged from $2.4 \%$ to $6.2 \%$ mainly due to good control measures which were being practiced by the mining health authorities (NMCC 1999).

In 2000 -2002 the incidence of malaria in Ndola ranged between 354 in 2000 and 484/ 1000 in 2002. Ndola has shown some reduction in the malaria incidence since IRS was re-introduced in 2003 as shown below. The incidence was 482/ 1000 in 2003 and has further reduced to 434/ 1000 in 2006 and now 381/ 1000 in 2007 (Ndola DHMT HMIS 2008). This is still high as it is above the national incidence of 358/ 1000. WHO estimates IRHS with insecticide coverage at $42 \%$ which is extremely low despite its effectiveness (Park 2007). The IRS objective in 2008 was to ensure that at least $85 \%$ of the targeted households in the 36 districts are protected by the end of 2008 in Zambia. Statistics shows that the national coverage of IRS have improved from 87\% in 2006 to $93 \%$ in 2007 (MOH 2008 national malaria action plan), of which Ndola had 89\% IRS coverage in 2006 and $90 \%$ in 2007 (Ndola RBM report 2007). Despite the high coverage there are problems that IRS is not functioning properly as the incidence of malaria is still high, hence the need to identify implementation challenges associated with IRHS in Ndola urban district. If effectively done IRS is supposed to reduce malaria incidence by $75 \%$, reason being that it reduces vector longevity, vector density and human contact in sprayed dwellings.

The other benefit of IRS is to contribute to the reduction of all causes of mortality by $20 \%$ in children under-five; High coverage of IRHS activities could reverse malaria trend and provide better economic growth as was evidenced in the past and currently in the konkola copper mines (Sipilanyambe and Nalishebo (2005). This study has been undertaken solely to find out the claims made by the NMCC and district councils that IRHS if successfully implemented will relatively reduce the prevalence of malaria in all the districts where this campaign is being carried out, with an estimated coverage of $90-100 \%$ by 2011 . If this is not true, then what are the challenges of IRHS campaign, what could be impeding this program?

\section{Research questions}

1. What policy problems exist in the execution of IRHS?

2. What institutional problems are associated with implementation of IRHS?

3. What operational problems are associated with implementation of IRHS?

4. How can the problems be addressed?

\section{Justification}

IRHS has been chosen by the researcher among the other malaria intervention package (which include intermittent presumptive treatment (IPT), insecticide treated nets (ITN), prompt and effective case management) as it reduces vector longevity, vector density, and contact between the vector and human beings in sprayed dwellings thereby reducing morbidity and mortality associated with this disease burden. The investigator wishes to find out factors contributing to high incidence of malaria in Ndola despite high coverage of IRS. The investigation of implementation problems associated with IRHS from a public health evaluation perspective has great potential for improving service delivery and reducing morbidity and mortality rates for malaria. The study finding will be able to highlight program needs, provide strategic direction for future programs by ensuring that best approaches are explored and used to refine the implementation process. Also, the findings may be incorporated into policy process to ensure that interventions that are effective are implemented. At the same time this study will generate first hand data based on lived local experiences and this will strengthen planning and implementation of IRS. It is envisaged that from this project, policy makers like NMCC, service providers and the community at large will understand some of these problems, which must be explored, and solutions put in place to ensure that IRHS interventions are a success if malaria is to be reduced in Zambia.

\section{Definition of key concepts}

In academic writings, it is just prudent from the outset that key words, which form the building blocks of a subject matter, are identified and defined. Essentially it makes the reader appreciate 
concepts when they reappear later in the text. Therefore, below are definitions of key concepts that have been used in this study.

Implementation is simply putting IRS strategies into action.

Challenges are simply difficulties or problems.

Indoor takes place inside the building.

Residual is small amount of insecticide that remains on the wall after spraying.

Household is a dwelling place.

Spraying consists of many drops of liquid insecticide applied on the wall.

Indoor residual household spraying is the procedure of applying liquid drops of insecticide which remain on the walls of the inside of the dwelling place for some time.

\section{The magnitude of the problem}

Malaria continues to be a major cause of preventable death. The annual burden includes 350 to 500 million clinical cases, more than 1 million deaths, and reduced economic growth (WHO \& UNICEF 2005). Malaria is one of the biggest healthcare problems on the African continent. Sub-Saharan Africa accounted for $89 \%$ of the world total malaria deaths in 2005. An estimated 25 to $35 \%$ of all outpatient consultations and 20 to $45 \%$ of hospitalizations in this region are due to malaria (WHO \& UNICEF 2005 in Marianela et al 2008).

Malaria incidence rates in Zambia tripled over the last three decades, from 121/1000 in 1976 to $428 / 1000$ in 2003, 412/ 1000 in 2006 and a remarkable reduction was achieved in 2007 and now is at 358/ 1000 (MOH HMIS 2007. However, the trend in the incidence of malaria in Ndola has shown some reduction since IRS was re-introduced in 2003 as shown below. The incidence was 482/ 1000 in 2003 and has further reduced to 434/ 1000 in 2006 and now 381/ 1000 in 2007. This is still high as it is above the national target of 358/1000. Having looked at the magnitude of malaria, it is imperative that we should look at the history of IRS as an intervention in malaria control.

\section{History of IRHS}

In Zambia studies have shown that IRHS with DDT reduced annual malaria prevalence from $74 \%$ to less than $1 \%$ in 1979 over a 2year period in konkola copper mine in Zambia (Tren \& Bate 2004). The study revealed that in Copperbelt province 180 villages were sprayed with insecticide in 1979 and parasite rate ranged from $2.4 \%$ to $6.2 \%$ mainly due to good control measures which were being practiced by the mining health authorities (NMCC 1999). The government of Zambia re-introduced IRS in 2003 in five pilot districts of which Ndola was one of them. Then it was increased to 15 districts in 2006/2007 spray season and now to 36 districts in the 2008/2009 spray season. The incidence of malaria by then was 482/1000in 2003 and five year after implementation of IRS the incidence is still high 385/ 1000 despite a high coverage of IRS. The coverage of IRS ranged from $83 \%$ in 2003, 86\% in 2004, 90\% in 2005, 89\% in 2006 and 90\% in 2007 (Simpungwe 2007). Five years have passed and IRS has been going on in Ndola. This study attempts to find out how IRS has been going on and what problems do the Ndola urban council experience in the implementation of this intervention in malaria control.

\section{Challenges in IRS programs}

\section{Law challenges}

Previously the malaria vector control programme in Zambia was largely governed by the mosquito extermination Act CAP. 557, 1944 which stipulated that the urban centers be covered $100 \%$ with two rounds of residual insecticide application every year. This led to success in eradication of malaria and by then it was a notifiable disease. This act needs review though it is supported by the public health Act cap 295. However, the current law focuses on Environmental safeguards. The main Act is the Environmental Protection and Pollution Control Act No. 12 of 1990 (CAP 204 of the Laws of Zambia). PART VII \& Pesticide Toxic Substance (PTS) statutory instrument (SI) No. 20 of 1994 Covers: Importation, exportation, manufacture, storage, distribution, sale, use, packing, transportation, disposal and advertisement of pesticides and toxic substances. 


\section{Policy1 challenges}

In principle, DDT was banned due to its adverse effects on the environment, like the high persistence in different environmental compartments and bioaccumulation and biomagnifications in living organisms, including human beings. Also, there are reports that this practice is currently threatened by the emergence of DDT resistance. In line with the Stockholm convention, Environmental council of Zambia (ECZ) allowed the MOH to import and use DDT for malaria control. The Stockholm conversion is the International Instrument that regulates pesticides organic pollutant (POPs) e.g. DDT, Chlordane, PCBs. Zambia signed the instrument in 2001and was ratified in 2006 .

No studies have been done to collect baseline information on levels of DDT in different matrices and monitor adverse effects it might have on the environment and human health (ECZ 2006). However, there are factors that influence IRS intervention in malaria control. These factors have been classified as; Law and policy challenges, institutional and operational challenges.

\section{Institutional 2 challenges}

Institutional factors influencing indoor residual household spraying range from poor quality of care and service delivery, resistance of insecticide, sustainability Of IRHS programme, poor timing and organization. These factors are valid as shown below:

\section{Operational3 challenges}

Operational challenges include; community's acceptance of IRS and inadequate logistics for IRS programme, replastering of houses. Human, technical and financial resources are often lacking to maintain a sustainable coverage (Coosmans and Canavale2 2000).

\section{Conclusion}

IRS is a method for community protection, and given its mode of action, the highest possible level of coverage is required to achieve the maximum impact on malaria transmission. Achieving this level of coverage and timing IRS correctly are crucial to realize the full potential of IRS.

\section{Objectives}

\section{General objectives}

To determine challenges associated with IRHS in Ndola urban district, with the view to improve IRHS intervention in malaria control.

\section{Specific objectives}

1. To determine if acceptability of IRS by the community affect IRS implementation.

2. To assess whether IRS guidelines are being adhered to by service providers.

3. To establish the extent to which availability of IRS logistics affect operations.

\section{Research questions}

1. What policy problems exist in the execution of IRHS?

2. What operational problems are associated with implementation of IRHS?

3. What institutional problems are associated with implementation of IRHS?

4. How can the problems be addressed?

\section{Conceptual definition of variables}

5. Knowledge is the information required

6. Compliance is simply obedience to set standards or guidelines.

7. Service delivery is carrying out a task

\footnotetext{
${ }^{1}$ What policy challenges exist in the execution of IRHS?

${ }^{2}$ What institutional challenges are associated with implementation of IRHS?

${ }^{3}$ What operational challenges are associated with implementation of IRHS?
} 
8. Quality care excellent service

9. Availability of logistics is ease of use

10. Acceptability of IRS is to accommodate

11.Indoor residual spraying challenges are difficulties experienced during spraying

\section{Chapter three: research methodology}

\section{Introduction}

This chapter describes the research methodology comprising the study design, study setting, study population, sample selection, data collection instruments, data collection techniques, ethical consideration, pre-testing, dissemination and utilization of results and limitation of the study. This study determined challenges associated with implementation of IRS in Ndola Urban District.

\section{Variables}

\section{Dependent variable}

- Indoor residual household spraying challenges

\section{Independent variables}

- Availability of logistics, Acceptability of IRS and Compliance with IRS guidelines.

\section{Research design}

This is a descriptive cross section study, which involves description and analysis of researchable objects with no intervention required. It is cross-sectional because the phenomena under study were captured during one data collection period. It also describes what exists about the phenomena and gives a clear picture of the situation. The study involved collection and presentation of data in a systematic manner, about evaluation of IRHS; challenges faced by service providers in Ndola urban district

\section{Research setting}

The research was conducted in Ndola urban district in Copperbelt province. Ndola city is 320 kilometers north of the capital city Lusaka, Zambia. The study was conducted at Ndola District council and public health offices along Broadway, where the service providers report before and after going into the field. Ndola district has a total population of 462,459 (Ndola DHMT HMIS 2008). The investigator chose Ndola urban district as a study site with the view of evaluating IRHS and challenges faced by service providers in Ndola urban district.

\section{Study population}

The sample consisted of all Program officers and spray operators (service providers) trained in IRS and participated in 2008 IRS spraying campaign, period October to November. The population has been selected because they include service providers of IRHS who are able to make decisions on this intervention and are more knowledgeable. Also, their attitude and practice towards IRHS may lead to effectiveness or ineffectiveness of this intervention in malaria control.

\section{Sample selection and sample size \\ Purposeful Expert Sampling (For service providers)}

All program officers were selected based on purposive expert sampling and all spray operators were purposively selected into the study. The spray operators were those specifically trained in IRS by Ndola district council and Ndola DHMT from the community. Expert purposive sampling was chosen despite its disadvantage of having unrepresentative sample. This is due to limited sample as there were only 129 trained service providers in IRS in Ndola urban district currently available, of these 120 were spray operators and 9 were program managers (1 project manager, 1 co-odinator, and 7 supervisors). All service providers were recruited for the study. However, out of 9 program officers only 8 (98\%) were interviewed as one declined to be interviewed or answer the questionnaire. Also, out of 120 spray 
operators, only 114 (95\%) were interviewed and 2 refused to be interviewed, while 4 of them stopped spraying before the exercise finished. A total of 122 respondents were accessed and there was 95\% response rate.

\section{Inclusion criteria}

- All programme officers/ spray operators trained in IRS, residing in Ndola urban district and participated in 2008 spraying campaign.

- All those who were willing to participate.

\section{Exclusion criteria}

- All programme officers (supervisors) and spray operators who were trained in IRS but not residing in Ndola urban district and did not participate in 2008 spraying campaign.

- All those who were not willing to participate.

\section{Data collection tools}

For this project, the researcher used a semi-structured questionnaire with spray operators and program officers. Expert checklist was used on program officers to validate responses from the semistructured interview schedule. The researcher used a semi-structured questionnaire (appendix IV and V) and an expert checklist (appendix VI).

\section{Validity}

This study employed two types of instruments, semi-structured interview schedule and a checklist. To ensure validity of data collection tool, pre-testing of the instrument was done in Luanshya to ensure clarity, precision and consistency of questions and where necessary adjustments were made on content and sequencing of questions. Expert checklist was used to validate responses from program officers. Triangulation method was used.

\section{Reliability}

The tool was modified from the national malaria indicator survey questionnaire. Reliability of the instrument was achieved by conducting a pre-test study in order to test the degree of accuracy with which the tools measured challenges in the implementation of IRS. After the evaluations of the pilot test to assess the extent to which the original questionnaire would grant us reliability, the researcher had an opportunity to perfect the questionnaire and checklist from the observed reactions of the respondents to the research instrument and their willingness to answer the questions. Deficiencies in the tool were overcome by making necessary changes where there were gaps. Also use of open-ended questions helped to bring out in-depth information so that all issues relating to challenges in IRS were discussed. In this study a Cronbach alpha coefficient of 0.70 was selected as a measure of reliability). If the item scores agree very closely with the universal score, then they should also be very closely related to one another as well. This way of assessing reliability is referred to as internal consistency, and is the approach presented in this study. Some questions that scored below 0.75 were dropped. In this way, reliability may be achieved.

\section{Data collection technique}

In this study two techniques (triangulation) were used to collect data. Face to face interview using semi-structured questionnaire, and observation using a checklist were conducted by the investigator. This enhanced collection of quality data and reduced information biases.

\section{Checklist}

A checklist containing policy, institutional and operational variables was used to obtain data from program officers. This tool was developed based on review of IRS guidelines and consultation from IRS experts. See appendix VII. 


\section{Semi-structured interview schedule}

The tool was modified from the National malaria indicator survey questionnaire (MOH/CSO 2008). It was modified as the questionnaire items were different and only two questions were on IRS. The questionnaire items were identified and adapted from review of the literature, statements and findings from previous studies, such as Hanson et al 2004; Musawenkosi 2004; Tren \& Bates 2004 to mention a few. The researcher will interview the experts in IRS (Program officers) and spray operators. This was taken care of through use of a checklist. Questionnaires consisted of both open and closed ended questions.

Data was collected from 4th week of October to 1st week of December 2008.

\section{Pre-test}

Pre-testing was done in Luanshya district at Thompson Hospital which was one of the IRS intervention areas, and had similar characteristics with those of the main study sites. The site was conveniently selected. Service providers were selected using expert purposive sampling and 12 participants were selected accounting 10\% of the sample for the main study (1 program officer and 11 spray operators). Pre-test helped the investigator to determine whether the variables were realistic, measurable and attainable. It also helps to make revisions in order to strengthen methodology, detect errors in the tool, and assess duration of interview schedule and appropriateness and clarity of questions.

\section{Ethical consideration}

Ethical clearance was obtained from University of Zambia Biomedical Research Ethics Committee. Since this study involves human subjects, verbal and written consent was obtained from the participants and from Luanshya district Health management team (pre-test), Ndola district council, Ndola district health management team and Copperbelt provincial health office. The purpose and nature of the study was explained to study participants. Those who refused to participate were assured that no privilege was going to be taken away from them. Those who agree to participate were requested to sign a consent form. There were no risks and immediate benefits to those who participated in the study. Respondents were in a natural setting and hence were not exposed to emotional or physical harm. Confidentiality and anonymity were maintained to all respondents as their names were not appearing on the questionnaire.

\section{Data process and analysis}

Textual data that was derived from open ended questions was analyzed using qualitative content analysis. A basic issue when performing qualitative content analysis of textual data is to decide whether the analysis should focus on manifest (visible) or latent (hidden) content only or both (Downe, 1992). This study covered both forms of content analysis since the data was in textual form, the data was categorized into themes and analyzed on the computer using the Non-numerical Unstructured Data Indexing (NUD*IST) computer package.

\section{Quantitative data}

Numeric non-textual data that was derived from the Expert checklists and semi-structured questionnaires, each day, all interview schedules were sorted out and edited for internal consistency, completeness, legibility and accuracy. Variables were defined; pre-coded and analyzed on the computer using the Social Science Statistical Package version 11.5. This study was analyzed by Univariate analysis to make frequencies then bivariate analysis to make cross tabulations.

Chi-square was used to determine the association of the qualitative variables and the outcome (IRS challenges). The qualitative variables include availability of IRS logistics, and acceptability of IRS. Confidence interval was set at $95 \%$ which was provided together with estimates. Cut off point for significance was set at 5\%, statistical significance was achieved if $\mathrm{P}$ value was 0.05 or less, thereby rejecting the null hypothesis. 


\section{Presentation of results}

\section{Introduction}

A total of 122 respondents were interviewed and there was a 95\% response rate. There were 9 program officers and only 8 were interviewed as one (1) declined to be interviewed. Spray operators were 120 , however, only 114 were interviewed, two refused and four could not be traced as they stopped spraying before the exercise could finish. Data for 8 program officers has been presented in narrative form and frequencies have been used instead of percentages as the sample was very small.

\section{Demographic characteristics}

In this study, most of the program officers were relatively new to the IRS program as more than half served for less than three years $(n=5)$. Environmental Health Technicians $(n=7)$ and of these three quarters were males $(\mathrm{n}=6)$. Table 4.1.1 Majority (66) of the spray operators were males and most of them $85 \%$ (56) had 0-2 years of experience, compared to $42 \%$ (41) of the females (table 4.1.1). Sex was not associated with experience in IRS ( $\mathrm{p}$ value $=1.000$ ). Most of these spray operators were between 18- 30 years $84.2 \%$ (96) (table 4.1.2).

\section{Policy guideline}

Majority of them were the table shows that program officers complied with most guidelines, except for use guidelines and environmental safeguards where $(n=4)$ said they complied, whereas 4 claimed they did not comply (table 4.2.1). The table shows that program officers complied with most guidelines, except for use guidelines and environmental safeguards where $(n=4)$ said they complied, whereas 4 claimed they did not comply (table 4.2.1).

When interviewed concerning the use of DDT and the problems program officers faced, it was noted that even though the policy guidelines were followed, there were serious problems with environmental safeguards and use guidelines. The program officers cited the following: Spillage of DDT on the ground, mechanisms of disposing off of DDT not yet established, DDT was not disposed off correctly as it was being spilled by the spray operators, spray operators used to refuse to carry DDT and could spill it on the ground. The checklist showed that the concrete floor had cracks, ventilation was inadequate, and the store room had one door instead of two, while other requirements were available (Table 4.2.2). Spray operators used chemicals invariably and most of them used icon, DDT, Fedona, k-othrine 43\% figure (4.2.1).

\section{Operational problems that exist in the execution of IRS}

When asked about how insecticides were carried from one household to another, more than half of the program officers revealed that spray men either carried the insecticides in plastic bags $(n=6)$ or in their pockets $(n=2)$. Three quarter of the program officers said the target was above $85 \%(n=6)$, while quarter did not know $(n=2)$. Program officers ranked their spray operator's level of knowledge to be above average $(n=5)$. Majority of the program officers revealed that household members were less likely to be found in their homes in the rain season $(n=6)$.

More than half of the program officers revealed that none of the insecticide is of much concern with resistance $(n=5)$, while less than half said Icon $(n=3)$. They also said that rate of acceptability in the community was average $(n=4)$. Almost all Program officers revealed that residents in the townships refuse IRS $(n=7)$. Program officers revealed that the reasons for the refusal of IRS by the community were that IRS made walls dirty, itching, not effective, excited bed bugs, affected recent plastering, warranted re painting of houses, spray operators are thieves and others just did not want. Three quarters of the program officers said they sometimes received IRS funds on time $(n=5)$ and more than half said the timely reception of funds affected their operations very much $(n=5)$. More than half of the program officers revealed that the procurement procedure was very short $(n=6)$, and half of them said it affected their operations very little $(n=4)$.

The checklist revealed that IRS guidelines were not available while spray pumps were inadequate (table 4.3.1). Table (4.3.2) shows that the spray men had almost all the protective clothes available. 
Table 4.3 .3 shows that majority $81.3 \%$ (87) of the respondents who said masks/ respirators were available experienced no problem while spraying compared to those who said they were not available $71 \%$ (5) experienced itching or rash, sneezing and difficulties in breathing. An association was done and (fishers exact test $\mathrm{P}$ value $=0.005$ significant at $\mathrm{p}<0.05 \alpha$ ) $* *$.

Majority 64\% (73) of the spray operators said that household members were less likely to be found in their homes in the rain season (graph 4.3.1). Table 4.3.4 shows that Majority 66\% (35) of spray operators who rated their level of training as good acquired more skills and had little problems in implementing IRS, compared to 12 who said their level of training was average to poor, with less skill and had very much to average operational problems. (Chi-square $=8.10, \mathrm{df}=2, \mathrm{p}$ value $=0.017$ significant at $\mathrm{p}<0.05) * *$.

Table 4.3.9 shows that acceptability of IRS in the community ranged from average to low mainly because of bad smell, itching effect, dirtying walls and recent spray/ replastering of houses $75.2 \%$ (70), while $24.7 \%$ (23) said lack of information, not effective and don't kill other insects. However, these proportions were significantly different. (Uncorrected chi-squire $4.36 \mathrm{p}=$ value 0.036 significant at $\mathrm{p}<0.05 \alpha) * *$. The highly recommended insecticide by the community was fedona $36.8 \%$ (42). Majority 57\% (65) of Spray operators revealed that they experienced itching with regard to use of IRS chemicals, while $20.2 \%$ (23) said they had no problems (table 4.3.7). More than half 51.8\% (59) of the spray operators revealed that reasons for refusal were due to bad smell, dirtens walls, and itching effects (table 4.3.8). Table 4.3.9 shows that acceptability of IRS in the community ranged from average to low mainly because of bad smell, itching effect, dirtying walls and recent spray/ replastering of houses $75.2 \%$ (70), while $24.7 \%$ (23) said lack of information, not effective and don't kill other insects. However, these proportions were significantly different. (Uncorrected chi-squire $4.36 \mathrm{p}=$ value 0.036 significant at $\mathrm{p}<0.05 \alpha) * *$.

$28.1 \%$ (32) of the Spray operators revealed that Repainting of walls was very much an operational problem (table 4.3.11). Almost half $44.7 \%$ (51) of the respondents disagreed that spraying was done at the same time every year (table 4.3.12). Majority $68.4 \%$ (78) of the respondents revealed that reasons for variation in spraying time were due to late arrival of funds and logistics (table 4.3.13).

Table 4.3.14 shows that more than half $76.3 \%$ (58) of the spray operators strongly disagreed/ disagreed that spraying was done at the same time every year and said reasons for variation were due to late arrival of funds/ logistics / poor timing/ planning, while $23.6 \%$ (18) said problems at national level. $($ Chi-square $=0.37, \mathrm{p}$ value $=0.54)$.

\section{Institutional Problems Associated with Implementation of IRHS}

The program officers revealed that staffing levels were adequate $(n=7)$ and the numbers fulfilled the establishment needs of the institution much $(n=3)$. The program officers agreed that they provided good services $(n=5)$. Almost all program officers said trained staffs were always available $(n=7)$ during spray time and more than half said trained staff availability affected operations very little $(n=5)$. Program officers said that Personnel attrition rates were very low $n=5$ and as such, operations were very little affected $(n=4)$. When asked about adequacy of storage facilities, more than half of the respondents disagreed $(n=5)$ that they had adequate storage facilities and half of them said it affected their operations much $(n=4)$.

The program officers claimed that they supervised spray operators daily $(n=7)$ and none had a spray schedule $(n=8)$. The program officers claimed that they adequately sensitized the community $(n=4)$, though none of them had a sensitization plan $n=8$. More than half of the program officers said that infrastructure resources were sometimes available $(n=5)$.

Facility checklist revealed that, showers were present $(+)$ but inadequate, whereas disposal bay, wash bay, change room and preparation bay were absent (-). All these were being constructed except for a change room (table 4.4.1). About half 54.4\% (62) of the Spray operators revealed that they were adequate to undertake the sought activities (table 4.4.2).

Table 4.4.4 shows that $43.9 \%$ (50) of the spray operators disagreed that wash bay and shower clog existed while, $3.5 \%$ (4) strongly agreed that they existed.

Table 4.5.1 shows varied solutions on the area of improvement given by program officers and spray operators. Most respondents indicated that areas needing improvement were giving IEC on importance 
of IRS and community sensitization $44.7 \%$ (51). The least suggested solution was the need for management and spray operators to work together and that supervisors needed to be involved in field work (table 4.5.1).

\section{Discussion of findings and conclusion}

\section{Introduction}

The main objective of the study was to determine implementation challenges associated with implementation of IRS in Ndola urban district.

This chapter discusses the findings in line with the research questions. The frame work that is used to present the research findings is driven by de4 Vaus, (2001) advice to researchers doing cross sectional research. The sound advice is that, critical issues that are similar are easily organised under a research question and that in this way, critical issues are unlikely to be missed. In this study therefore the themes that represent the key research questions were used to show the findings and these are;

a. Theme I Policy Problems that Exist in the Execution of IRHS

b. Theme II Operational Problems that Are Associated with Implementation of IRHS

c. Theme III Institutional Problems that Are Associated with Implementation of IRHS

d. Theme IV Solutions to the Problems (Social Actors Accounts)

The chapter is composed of the discussion of the findings using extant data of previous research. This is done in order to illuminate the research problem, to elaborate and support facts with existing data. In this way, the study would grant convergent validation to the data. Limitations and strengths of the study are presented since these play an important role in making suggestions for future research. Then we wind up with the conclusion and recommendations. This leads us to the demographic characteristics of our respondents.

\section{Demographic characteristics of service providers and spray operators}

In this study, majority of program officers were Environmental Health Technicians $n=7$ and Most of them were relatively too new to the IRS program as more than half had served for less than three years $n=5$, noting that it has been in operation for six year. This could influence their supervisory skills to guide the spray operator. Just like program officers, most $85 \%$ (96) of the spray operators were males and were relatively new in the IRS program as three quarters of them had served less than three years, compared to $42 \%$ (41) of the females (table 4.1.1) and this could affect their skills negatively. The reason could be that exposure to insecticide limits the number of years one has to work as a spray operator which is 2-3 years and not beyond. However, sex was not associated with experience in IRS (p value 1.000). Majority $84.2 \%$ of the spray operators were in the age group 18-30 years (table 4.1.2) and most of them were males. The explanation could be that, this is the productive age group which is more energetic to move from one place to another in the field and could be unemployed. CSO (2003) documented that youth unemployment is still high with $21 \%$ of youths aged 20-24 years being unemployed. The reason for having more males could be that they are readily available and had to provide for their families, than females of the same age group who could be married.

\section{Policy challenges}

Our findings revealed that insecticides were not used and disposed of according to the dictates of the policy. The IRS program seems to fare well when it comes to complying with storage, disposal and transport guidelines $(n=7)$. However, the IRS program managers have a serious problem in offering guidance in ensuring that the policy guidelines are adhered to. Program officers comply with most guidelines, except for use guidelines and environmental safeguards, $\mathrm{n}=4$ said they complied, whereas $\mathrm{n}=4$ claimed they did not comply (table 4.2.1). When asked why they were not able to comply with DDT guidelines they revealed that Spray operators used to spill DDT on the ground $n=4$. Basically, all the spray operators are trained during cascade training programme. This is carried out before the start of IRS campaign. The performance of the spray operators depends on the skills of the master trainers and supervision during training and field exercise during the campaign. There was spillage during

\footnotetext{
${ }^{4}$ De Vaus, A.D. (2001) Research Design in Social Research. London: Sage.
} 
chemical mix and washing of pumps after spray exercise because there was overcrowding at the wash bay because everyone was rushing and tired. In Ndola this could be attributed to inadequate infrastructure like absence of a wash bay where washing of spray pumps can be done, then the drums which were being used to clean and dispose of the left-over chemicals in the pumps. Chapin and Wasserstrom (1981) documented that Spraying programs (especially using DDT) were curtailed due to concerns over safety and environmental effects, as well as problems in administrative, managerial and financial implementation.

A cursory look at their operational office using a checklist showed that most critical elements were adhered to whereas others were not adhered. The Concrete floor had cracks, ventilation was inadequate, and the store room had one door instead of two. A sign post, thermometer, insecticides and a stock record card were available (Table 4.2.2). We believe that construction of a wash bay and shower clog and refurbishment of store room will greatly reduce these policy challenges.

The findings revealed that Spray operators used chemicals invariably according to the type of structure and $43 \%$ used icon, Fedona, k-othrine and DDT, figure (4.2.1). Icon, Fedona and K-othrine were used for formal structures and DDT was used for informal mud houses. These chemicals were among the chemicals recommended for IRS by the WHO standard protocol (WHO 1998). When program officers were asked about resistance to chemicals used, more than half of the program officers revealed that none of the insecticide is of much concern with resistance $n=5$, while $n=3$ said Icon. This finding is in line with Chanda et al (2008) who documented that baseline insecticide susceptibility test conducted on the three malaria species to these chemicals in Zambia showed that there was $100 \%$ susceptibility. Therefore, insecticide resistance was not a factor in this study

\section{Operational challenges}

Spray operators noted that IRS was punctuated with a lot of operational problems. The findings of this study revealed that availability of protective materials does influence operational problems as shown in table 4.3 .3 majority $81.3 \%$ (87) of the respondents who said masks/ respirators were available experienced no problems while spraying compared to those who said they were not available $71 \%$ (5) experienced itching or rash, sneezing and difficulties in breathing. An association was done and the result was statistically significant $(\mathrm{P}$ value $=0.005)$. Therefore, we reject the null hypothesis which states that there was no association between availability of masks/ respirator and experienced problem with chemicals. Therefore, availability of protective clothing is significantly associated with operational problems. This implies that those who had protective clothing and used them correctly were less likely to experience operational problem associated with exposure to chemicals unlike those who did not have masks/ respirators. Some spray operators had their gum boats stolen and were using their own canvases, while others lost their respirators and were using pieces of clothes to cover their nose while spraying. Also, more emphasis should be placed on the importance of using protective clothing during spraying for the safety of the spray operators.

The findings of this study have revealed that level of training does influence operational problems of spray operators and the relationship was found to be statistically significant ( $\mathrm{p}$ value $=0.017$ ). $66 \%$ of Spray operators who rated their level of training as good acquired more skill and had less problems in implementing IRS than 12 who had average to poor training with less skills and had very much to average operational problems in implementing IRS (table 4.3.4). Therefore, we reject the null hypothesis which states that there is no association between level of training and operational problems. The findings are in line with Musawenkosi (2004) who reported that lack of proper supervision and/or skilled personnel is another mitigating factor because effective application of residual insecticides requires properly trained individuals. Therefore, there is need for NMCC to improve on supervision and training must be strengthened. The findings revealed that, fedona (Alphacyperthrin) was highly recommended by the community $36.8 \%$ (figure 4.3.2). These findings are in line with Rowland et al (2000) on use of Alphacyperthrin in IRS in Pakistan who revealed that, many people expressed appreciation for the spray campaign, since no persistent odour or residue was evident after spraying, and because both nuisance and vector mosquitoes were controlled. Also Curtis (1986) documented that Pyrethroids such as Deltamethrin and lambda-cyhalothrin are usually much more acceptable to householders because they leave no visible deposit on walls. We can infer that when IRS is effectively 
done using the acceptable chemical by the community, IRS refusals are more likely to reduce thereby increase the coverage and reduce the disease burden.

The study discovered that there was a significant relationship between sex and insecticide highly acceptable by the community ( $\mathrm{p}$ value 0.036 ). $44.6 \%$ (29) of the spray operators who said the most recommended chemical by the community was Fedona were males, compared to $26.5 \%$ (13) of the females (table 4.3.5). This result was statistically significant thereby rejecting the null hypothesis which states that there is no association between sex and insecticide highly recommended by the community.

While the spray operators were in the field, they experienced adverse effects related to contact with IRS chemicals. The study findings showed that Majority 57\% of the Spray operators revealed that they experienced itching with regard to use of IRS, while $20.2 \%$ said they had no problems (table 4.3.7). This could be attributed to Exposure of the worker to the pesticides during preparation or IRS, however this can be greatly reduced if the worker follows best practices, Biscoe et al (2007) in RTI international (2007). Unlike the spray operators, complaint of itching effect of Icon from the community was reported as some of the challenges experience during the spray campaign (Ndola RBM report 2007). Therefore, lack of skill and knowledge may influence practice towards safety measures in handling the insecticides there by posing operational challenges

The study revealed that almost all $(n=7)$ program officers said that residents in the townships refuse IRS. Also, more than half $51.8 \%$ of the spray operators revealed that reasons for refusal were varied and the most noted was due to bad smell, dirtens walls, and itching effects while $18.4 \%$ said lack of information (4.3.8). Lack of information on IRS implied that IEC messages were inadequate and poor and should be strengthened so that refusals are reduced and coverage increased to $100 \%$ in 2011 . This finding was complimented by program officers who said that the reasons for the refusal of IRS by the community were that; IRS made walls dirty, itching, not effective, excited bed bugs, affected recent plastering, warranted re painting of houses, spray operators are thieves and others just did not want. This was in line with Simpungwe (2007) who documented that they faced resistance in some of the compounds during the 2007 spraying program. Similar findings were reported in other studies by Gunasekaran et al (2005) Mnzava et al (1998) and Musawenkosi (2004) that Wall decolourization, bad smell, increase in bed bug nuisance, were some of the reasons attributed for the refusal. Curtis (1986) and Thurow (2001) also highlighted that Many residents resist spraying of DDT reasons being; the smell lingers, and DDT leaves stain on the walls and may need urgent attention.

In this study, majority $73.7 \%$ of the respondents said that acceptability of IRS in the community was average (graph 4.3.2). This was also revealed by program officers who said that rate of acceptability of IRS in the community was average $n=4$. The explanation could be attributed to refusals. Therefore, involvement of householders in collaboration with community representatives in IRS intervention is important Coosmans and Carnevale2 (2000). Resistance from residents prevents a high percentage of the homes being effectively sprayed; the effectiveness of the intervention is greatly reduced Curtis (1986) and Gladwell (2001). Also, Rowland et al (2000) revealed that use of Alphacyperthrin in IRS further revealed that, many people expressed appreciation for the spray campaign, since no persistent odour or residue was evident after spraying, and because both nuisance and vector mosquitoes were controlled.

The study also revealed that there was a significant association between acceptability of IRS and reasons for refusal of IRS by the community (P value 0.036). The findings showed that out of 93 spray operators who rated acceptability of IRS to be between average and low, more than half $75.2 \%$ (70) of them said reasons for refusal were mainly; bad smell, dirtying walls, itching effect and recent spray/ replastering of homes, while $24.7 \%$ (23) said it was due to lack of information, not effective and don't kill other insects (table 4.3.9). This was in line with Simpungwe (2007) who reported that complaint of rat flea in informal structures was among the challenges experienced in 2007 spray season. This is supported by varied reasons given by spray operators. In view of this NMCC in conjunction with $\mathrm{MOH}$ need to consider using of chemicals which are highly acceptable in the community so that acceptability of IRS in the community can be improved thereby increasing IRS coverage to $100 \%$ by 2011 and reduce malaria incidence. 
The findings of this study have revealed that there was no association between most recommended chemicals and acceptability of IRS (P value $=0.565)$. More than half $52.7 \%(48)$ of the respondents reported that the most recommended chemicals were fedona and k-othrine and said acceptability of IRS in the community was average compared to $42.9 \%$ (9) who said it was high (table 4.3.10). However, these proportions were not statistically different. Therefore, we fail to reject the null hypothesis which states that there was no association between recommended chemicals and acceptability of IRS. This implies that acceptability of IRS could not be accounted to highly recommended chemicals but there could be other factors related to operational problems. This is in line with Musawenkosi (2004) who reported that, the first spray is generally well accepted by the householder, but if the comments of the population are not considered, doors will be closed the following spray rounds and spray coverage will be insufficient.

The study found that repainting / replastering of homes was a significant problem which could be occasioned by bad smell and wall staining and was not a new finding. $28.1 \%$ of the Spray operators revealed that Repainting of walls was very much an operational problem (figure 4.3.3). This finding supports that of Mnzava et al (1998) and Gladwell (2001) who reported that after spraying the houses, the community has a tendency of replastering the walls because of the presence of DDT stains. Other findings were those for Mabaso, et al (2004), Tren and Bates (2004) who documented that stains causes some villagers to avoid spraying of their homes or to resurface the wall, which eliminates the residual insecticidal effect of the spraying. A study by Gunasekaran (2005) further revealed that in replastered walls anophyles fluviatilis mortality were once or twice reduced to $27 \%$ and $13 \%$ respectively. At week 16, the mortality was only $19 \%$ on walls which had not been re-plastered and, during this period, re-plastering twice brought down the mortality to 5\%. This practice compromises the effectiveness of IRS program and calls for evaluation of IRS messages targeted towards the community members. Therefore, the communities under this programme need to be educated not to plaster homes until after 6months of spraying exercise, because if they did so, mosquitoes won't die and malaria will continue killing people especially pregnant women and children under -5 who are most vulnerable.

The study revealed that almost half $44.7 \%$ of the respondents disagreed that spraying was done at the same time every year table (4.3.12), and this was confirmed by both the program officers and spray operators. However, this is contrary to what the IRS guidelines stipulate. The IRS guidelines states that, spraying should be at regular intervals so as to ensure that an effective residue is in place during the whole transmission season. Smith et al (1995) and Deressa (2007) reported that effectiveness may be diminished if spray rounds are inappropriately timed in relation to the transmission season. There are various reasons why the situation is like this. Majority $68.4 \%$ of the spray operators said that reasons for variation in spray times were due to late arrival of funds and logistics (table 4.3.13). Program officers also confirmed that they sometimes received IRS funds on time $n=5$ and more than half said the timely reception of funds affected their operations very much $n=5$ and was significant. Similar findings were documented by MOH (2006) that there was delay in release of funds. WHO (2006), reported that full potential of IRS can be achieved through high coverage and good timing? Therefore, there is need for NMCC to ensure that IRS logistics and funds are released on time so that IRS campaigns starts on time according to the action plan before the malaria transmission season.

The findings further revealed that there is no association between spraying time and reasons for variation in spraying ( $\mathrm{p}$ value $=0.54$ ). The study showed that more than half $76.3 \%$ (58) of the spray operators strongly disagreed/ disagreed that spraying was done at the same time every year and said reasons for variation were due to late arrival of funds/ logistics / poor timing/ planning though were influenced by many factors, while $23.6 \%$ (18) said problems at national level. This shows that there could be other operational factors that influences spray time.

In general, the operational problems that we have seen are due to lack of clear link between the program activities and the organization's key strategic priorities

\section{Institutional problems associated with implementation of IRHS}

The findings revealed that staffing levels were adequate and this was confirmed by all respondents. $54.4 \%$ of the Spray operators revealed that they were adequate to undertake the sought activities (table 
4.4.2) and the numbers fulfilled the establish needs of the institution for effective implementation of IRS activities. Also, program officers said trained staff were always available $(n=7)$ and affected operations very little $(n=5)$, while attrition of staff were low $(n=5)$ and therefore staffing levels and attrition of trained staff were not a factor in this study.

Ndola has severe lack in infrastructural resources to support IRS. According to the findings of this study, almost half $43.9 \%$ of the respondents disagreed that shower and wash bay facilities were adequate, while $3.5 \%$ strongly agreed that they were adequate (table 4.4.4). Verification using a checklist confirmed that wash bay was not available and showers were present but inadequate causing institutional problems. The study also revealed that all (100\%) of the spray operators revealed that transport was available through hired, however these transports used did not meet the transport regulations and were very expensive. The vehicles used, carried both chemicals and spray operators and did not have warning sign for chemicals. Also, majority $84.2 \%$ confirmed that they had no problems regarding transport (table 4.4.3). However, a few 2.6\% reported knocking off late and 5.3\% said it affected their work. A checklist showed that transport was not available for IRS but it was hired. Serious inadequacies were evident in transport, disposal bay, preparation bay, wash bay, and change rooms were not available and shower clog were not sufficient. As a result, the spray operators used to bath and wash their overalls at their homes which was a wrong practice, as all washing is supposed to be done in a washing bay. This finding was in line with challenges documented by $\mathrm{MOH}$ (2008) action plan that transport was inadequate in most IRS districts. Therefore, insufficient logistic highly impinged on daily operations of service providers in IRS and contributed to non-adherence to some of the policy guidelines. These findings were also highlighted by Simpungwe (2007) who said that transport was hired and there was need for a wash bay, shower and clogs for males and females. However, on the positive aspect the wash bay and shower clog were being constructed. Therefore, $\mathrm{MOH}$ in conjunction with NMCC should consider procuring vehicles for transportation of chemicals and IRS logistics as well as IRS service providers during the IRS campaign.

When asked about adequacy of storage facilities, more than half $(n=5)$ of the program officers disagreed that they had adequate storage facilities and half $(n=4)$ of them said it affected their operations much. These findings are in line with what was reported by the MOH in 2008 national malaria action plan that there were inadequate storage facilities in most IRS district. However, these findings contradict what was document by Simpungwe (2007) in the Ndola RBM report that Ndola had adequate storage facilities. However, both the program officers and spray operators were in agreement that storage facilities were inadequate as highlighted in their recommendations (table 4.5.2), this was also verified using a checklist. Checklist also verified that storage facilities were inadequate such that chemicals and equipments like spray pumps were stored in the same room and ventilation was inadequate. Among issues identified for global funding round 7 was improving storage facilities in 2007 action plan, however this issue has not yet been addressed in Ndola as such storage facilities does not meet the standard guideline as stipulated by WHO and ECZ. Also Spray pumps were inadequate 117 were available against 120 spray operators. This is mainly the problem of inadequate logistics which needs immediate attention to improve IRS coverage. Also, IRS guidelines were evidently missing and had negative impact on daily operations as they are guiding principles to effective implementation of IRS. In view of this there is need for NMCC to ensure that money for building and refurbishment of store room is released so that the existing infrastructure can be improved according to $\mathrm{WHO}$ and ECZ guidelines. Also, there is need to ensure that enough logistics are provided like spray pumps to the districts on time.

\section{Solutions to the problems (Social actors accounts)}

When program officers and spray operators were asked as to how the various problems could be solved, there proposals were targeted at improving operations and institutional structures (table 4.5.1). There was very little related to policy though policy measures have a direct bearing on operations and institutional structures. Spray operators gave varying reasons and most $44.7 \%$ (51) respondents indicated that areas needing improvement was giving IEC on importance of IRS and community sensitization. The least suggested solution was the need for management and spray operators to work together and that supervisors needed to be involved in field work $0.8 \%$ (1). This is very crucial and 
shows that IEC messages on IRS are inadequate and need to be strengthened. However, one would note that some recommendations (table 4.5.2) are cross cutting and this is because of a relationship based on simultaneous occurrence or sequential occurrence. There is need for policy and decision makers to carefully analyze and see how best the solutions suggested by service providers can be incorporated at national level to solve some of the challenges in the implementation of IRS.

\section{Limitations and strengths of the study}

The study was conducted without the involvement of communities who happen to be consumers of the service and as such their views could have added impetus to the study. The limitations of community involvement were obvious in academic research on account of time and cost. But we have the views of the program officers and thus, we do not feel that these limitations would have caused major changes in our findings.

Notable strengths of the study are that it is the first known research to focus explicitly on IRS in Ndola from a public health perspective. This study is an initial step toward addressing the various problem areas that program officers and spray operators sighted that constrained service delivery. The study also contributes towards the scientific world knowledge on program evaluation and it is hoped that the results could be used by the program manager for purposes of program design improvements and operations. Population study has been done and findings can be generalized to Ndola urban district and other IRS districts in the country despite purposive sampling because they have similar characteristics like Ndola.

\section{General conclusion}

The study findings have policy, operational and institutional implications. Evaluation of IRS program in Ndola has shown that IRS can substantially reduce the incidence of malaria and its associated economic consequences, and should be promoted. The findings have shown that IRS target can be maintained from $85 \%$ to $100 \%$ through increased IEC in the community which can reduce the percentage of refusals so that IRS coverage goes up. It has clearly demonstrated that acceptability of IRS in the community was average because the percentage of refusals was very high and reasons included mainly; dirtens walls, Bad smell, itching effect and lack of information on IRS as the IEC was poor. This protocol found that there are logistic problems surrounding IRS program which may hamper reaching 100\% target by 2011 these mainly include; inadequate spray pumps, and infrastructure, lack of transport and late arrival of funds/ logistics for IRS program at the District. The skills of spray operators were negatively associated with their level of training. The data in this review also demonstrate a striking pattern relating to the negative implications of non-adherence to policy and lack of program integrated monitoring and evaluation to address institutional and operational plans. It can be said that because of lack of strict adherence to policy guidelines and a poor institutional structure, have resulted into the serious operational problems that we have highlighted. The IRS program seems not to take account of the views of all stakeholders and this requires addressing through community participatory research action.

\section{Tables and figures}

Table 4.1.1. Sex in relation to experience in IRS of spray operators $(n=114)$

\begin{tabular}{|l|l|l|l|l|}
\hline \multicolumn{2}{|l|}{ Sex } & \multicolumn{2}{|l|}{ Experience in IRS } & Total \\
\cline { 3 - 5 } & & $0-2 y r s$ & $3-4 y r s$ & \\
\hline & Male & $56(85 \%)$ & $10(15 \%)$ & $66(100 \%)$ \\
\hline & Female & $41(42 \%)$ & $7(41 \%)$ & $48(100 \%)$ \\
\hline & Total & $97(85 \%)$ & $17(15 \%)$ & $114(100 \%)$ \\
\hline
\end{tabular}

Table 4.1.2. Age $(n=114)$

\begin{tabular}{|c|l|l|l|}
\hline \multicolumn{2}{|l|}{ Age of spray operators } & Frequency & Percent \\
\hline \multicolumn{1}{|c|}{ 18-30 years } & 96 & 84.2 \\
\hline \multicolumn{2}{|c|}{$31-40$ years } & 18 & 15.8 \\
\hline
\end{tabular}




\begin{tabular}{|l|l|l|l|}
\hline & Total & 114 & 100 \\
\hline
\end{tabular}

Policy problems that exist in the execution of IRHS.

Table 4.2.1. compliance to DDT guidelines

\begin{tabular}{|l|l|l|l|}
\hline Challenge & Problem area & \multicolumn{2}{l|}{ Response Type } \\
\cline { 3 - 5 } & & Yes & No \\
\hline $\begin{array}{l}\text { If you do use DDT, to what extent do you apply } \\
\text { procedures in case of storage guidelines? }\end{array}$ & Policy challenge & 7 & 1 \\
\hline $\begin{array}{l}\text { If you do use DDT, to what extent do you apply } \\
\text { procedures in case of use of guidelines? }\end{array}$ & Policy challenge & 4 & 4 \\
\hline $\begin{array}{l}\text { If you do use DDT, to what extent do you apply } \\
\text { procedures in case of disposal guidelines? }\end{array}$ & Policy challenge & 7 & 1 \\
\hline $\begin{array}{l}\text { If you do use DDT, to what extent do you apply } \\
\text { procedures in case of environmental safe guards? }\end{array}$ & Policy challenge & 4 & 4 \\
\hline $\begin{array}{l}\text { If you do use DDT, to what extent do you apply } \\
\text { procedures in case of transportation guidelines? }\end{array}$ & $\begin{array}{l}\text { Operational } \\
\text { challenge }\end{array}$ & 6 & 2 \\
\hline
\end{tabular}

Table 4.2.2. store room checklist

\begin{tabular}{|c|c|c|c|c|}
\hline No & Item & Present (+) & Absent (-) & Comments \\
\hline 1. & Thermometer & $(+)$ & & \\
\hline 2. & \begin{tabular}{l}
\multicolumn{2}{l}{ Insecticide } \\
$-\quad$ Name \\
$-\quad$ Expirely date
\end{tabular} & $(+)$ & & $\begin{array}{l}\text { All had } \\
\text { expiry } \\
\text { dates }\end{array}$ \\
\hline 3. & $\begin{array}{l}\text { Concrete floor } \\
\text { - } \quad \text { Cracks } \\
\text { - } \quad \text { No cracks }\end{array}$ & $(+)$ & & Had cracks \\
\hline 4. & 2 Doors & $(+)$ & & $\begin{array}{l}\text { Only one } \\
\text { door }\end{array}$ \\
\hline 5. & Sign post & $(+)$ & & \\
\hline 6 & Stock record & $(+)$ & & \\
\hline 7. & Ventilation & $(+)$ & & $\begin{array}{l}\text { but } \\
\text { inadequate }\end{array}$ \\
\hline 9. & $\begin{array}{ll}- & \text { Overall } \\
\text { - } & \text { Rubber gloves } \\
\text { - } & \text { Face shields/goggles } \\
\text { - } & \text { Masks } \\
\text { - } & \text { Boots }\end{array}$ & $(+)$ & & Adequate \\
\hline
\end{tabular}

\section{Operational problems that exist in the execution of IRS}

Table 4.3.1. Facilities checklist

\begin{tabular}{|l|l|l|l|l|}
\hline 1 & IRS guidelines & & $(-)$ & Were not available \\
\hline 2 & Spray pumps & $(+)$ & & Not adequate only 117 \\
\hline
\end{tabular}

Graph 4.3.1 Season when household members are less likely to be found in their homes for IRS $(\mathbf{n}=114)$ 


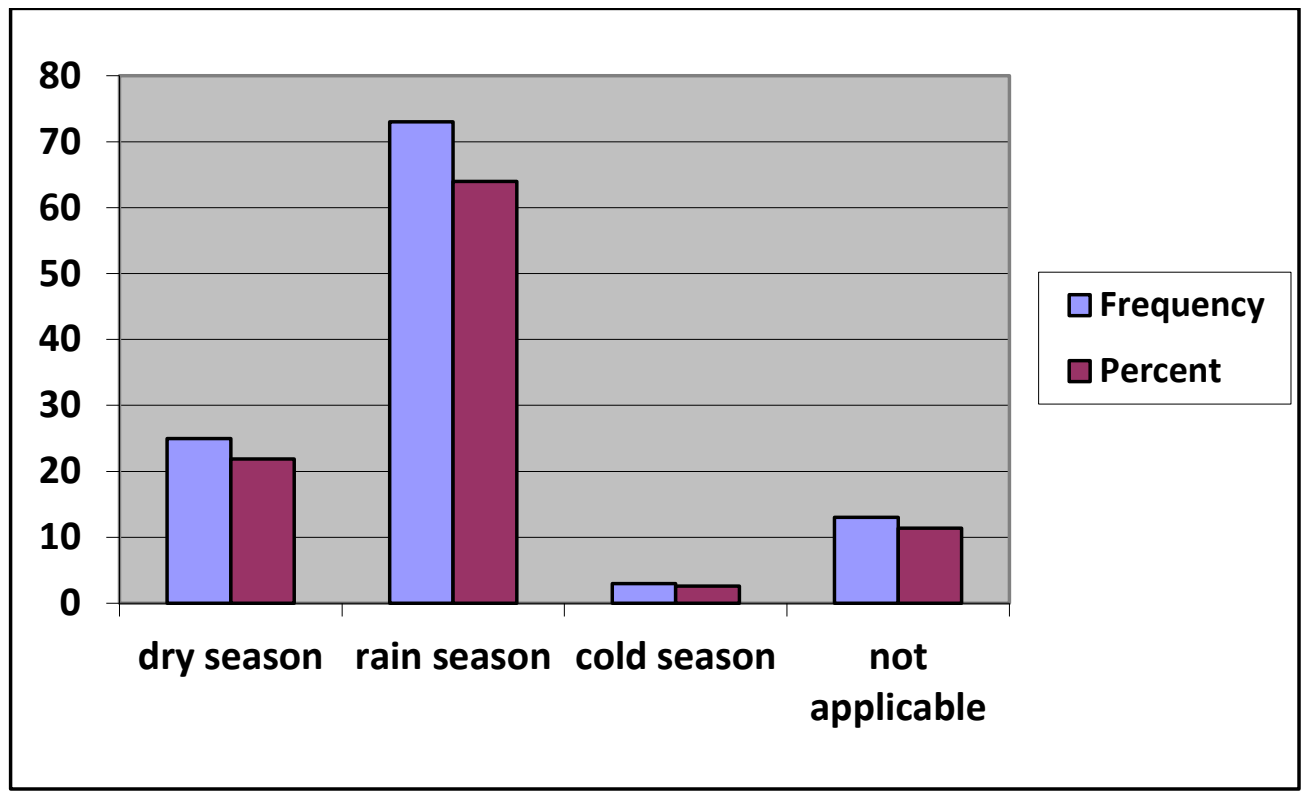

Table 4.3.4. training by level of contribution to operational problems

\begin{tabular}{|l|l|l|l|}
\hline Rating of training & \multicolumn{3}{|l|}{ level of contribution to operational problems } \\
\hline & $\begin{array}{l}\text { Very much to } \\
\text { average }\end{array}$ & Little to very little & Total \\
\hline Average to poor & $12(70.5 \%)$ & $5(29.4 \%)$ & $* 17(100 \%)$ \\
\hline Good & $18(33.9 \%)$ & $35(66 \%)$ & $53(100 \%)$ \\
\hline Very good & $15(34 \%)$ & $29(65.9 \%)$ & $44(100 \%)$ \\
\hline Total & $45(39.4 \%)$ & $69(60.5 \%)$ & $114(100 \%)$ \\
\hline
\end{tabular}

Table 4.3.8. Reasons for refusal of IRS by the community $(n=114)$

\begin{tabular}{|l|l|l|}
\hline Reasons for refusal & Frequency & Percent \\
\hline not effective, don't kill insects & 2 & 10.5 \\
\hline bad smell, dirtens walls, itching effects & 59 & 51.8 \\
\hline recent spraying/ replastering of houses & 1 & .9 \\
\hline itching effects/ not effective & 18 & 15.8 \\
\hline Lack of information & & 21.1 \\
\hline Total & 24 & 100.0 \\
\hline
\end{tabular}

Table 4.3.9. Rating acceptability of IRS in the community by reasons for refusal $(n=114)$

\begin{tabular}{|l|l|l|l|}
\hline \multirow{2}{*}{$\begin{array}{l}\text { Rate of } \\
\text { acceptability }\end{array}$} & \multicolumn{2}{|l|}{ Reasons for refusal of IRs } \\
\cline { 2 - 4 } & $\begin{array}{l}\text { itching effect, bad smell, } \\
\text { dirtens walls, recent } \\
\text { spray/ replastering of } \\
\text { houses }\end{array}$ & $\begin{array}{l}\text { Lack of } \\
\text { information, } \\
\text { not effective, } \\
\text { don't kill } \\
\text { insects }\end{array}$ & Total \\
\hline Very high- high & $11(52.3 \%)$ & $10(47.6 \%)$ & $* 21(100 \%)$ \\
\hline Average - low & $70(75.2 \%)$ & $23(24.7 \%)$ & $93(100 \%)$ \\
\hline Total & $81(71 \%)$ & $33(28.9 \%)$ & $114(100 \%)$ \\
\hline
\end{tabular}


Table 4.3.10. Chemicals most recommended by level of acceptability of IRS in the community $(n=112)$

\begin{tabular}{|l|l|l|l|}
\hline \multirow{2}{*}{$\begin{array}{l}\text { Chemicals } \\
\text { recommended }\end{array}$} & \multicolumn{2}{|l|}{$\begin{array}{l}\text { Level of Acceptability of } \\
\text { IRS }\end{array}$} & Total \\
\cline { 2 - 5 } & High & Average & \\
\hline $\begin{array}{l}\text { Fedona \& K- } \\
\text { othrine }\end{array}$ & $9(42.9 \%)$ & $48(52.7 \%)$ & $57(50.9 \%)$ \\
\cline { 2 - 4 } & & & \\
\hline Icon \& DDT & $12(57.1 \%)$ & $43(47.3 \%)$ & $55(49.1 \%)$ \\
\cline { 2 - 4 } & & & \\
\hline Total & $21(100 \%)$ & $91(100 \%)$ & $112(100 \%)$ \\
\cline { 2 - 4 } & & & \\
\hline
\end{tabular}

Figure 4.3.3 Extent of agreement that replastering of walls is an operational problem $(n=114)$.

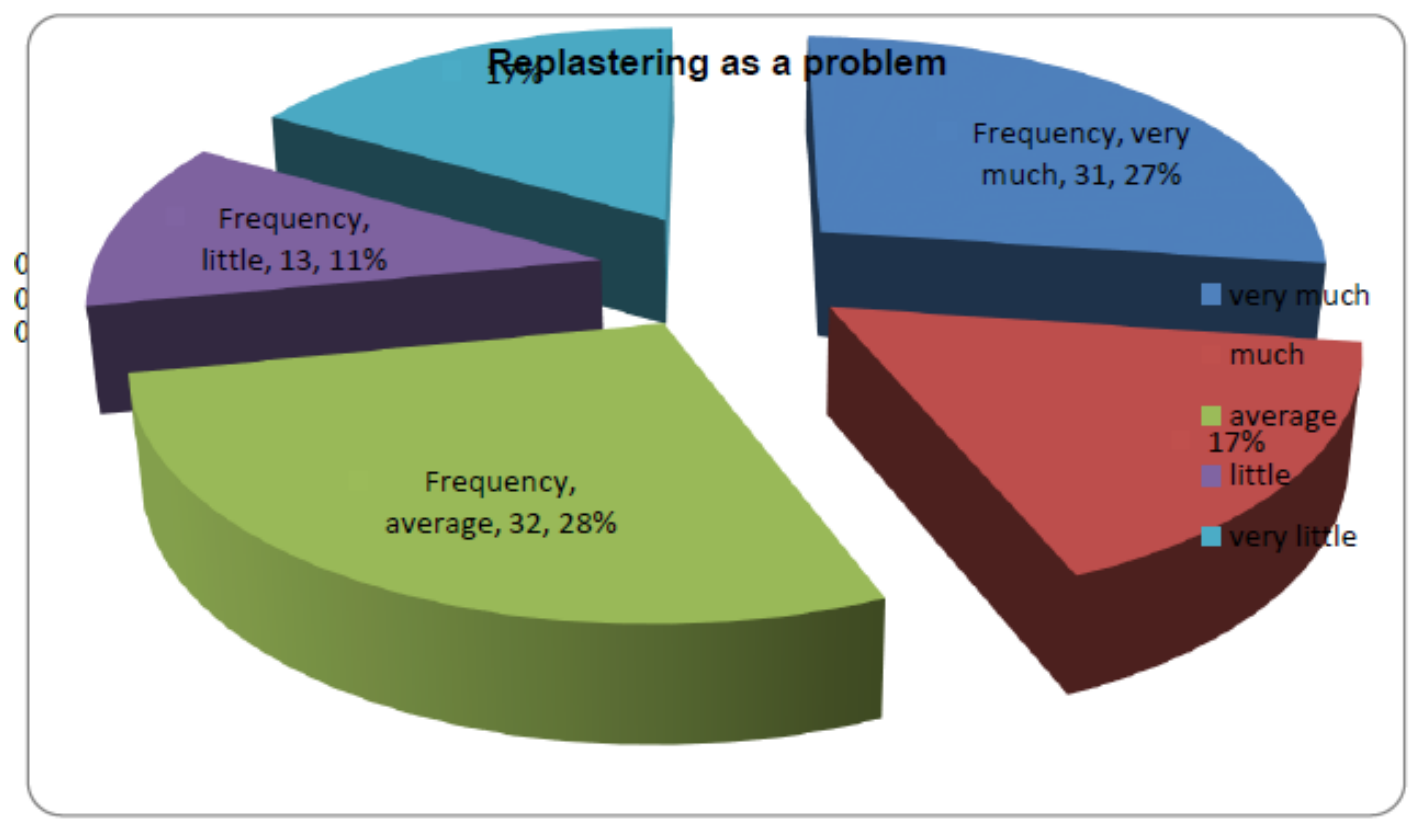

Table 4.3.11. level of agreement that repainting of walls as an operational problem $(n=114)$

\begin{tabular}{|l|l|l|}
\hline Level of agreement & $\begin{array}{l}\text { Frequenc } \\
\text { y }\end{array}$ & Percent \\
\hline very much & 32 & 28.1 \\
\hline Much & 27 & 23.7 \\
\hline Average & 27 & 23.7 \\
\hline Little & 9 & 7.9 \\
\hline very little & 19 & 16.7 \\
\hline Total & $\mathbf{1 1 4}$ & $\mathbf{1 0 0 . 0}$ \\
\hline
\end{tabular}

Table 4.3.12. Extent of agreement that spraying is done at the same time every year $(n=114)$.

\begin{tabular}{|l|l|l|}
\hline $\begin{array}{l}\text { Level of } \\
\text { agreement }\end{array}$ & Frequency & Percent \\
\hline strongly agree & 15 & 13.2 \\
\hline Agree & 41 & 36.0 \\
\hline Disagree & 51 & 44.7 \\
\hline strongly disagree & 7 & 6.1 \\
\hline Total & 114 & 100.0 \\
\hline
\end{tabular}


DOI: 10.21522/TIJPH.2013.SE.19.01.Art013

ISSN: $2520-3134$

Table 4.3.13. Reasons for variation in starting time of spraying $(n=114)$

\begin{tabular}{|l|l|l|}
\hline Reasons for variation & Frequency & Percent \\
\hline $\begin{array}{l}\text { late arrival of funds/ } \\
\text { logistics }\end{array}$ & 78 & 68.4 \\
\hline poor timing/ planning & 7 & 6.1 \\
\hline problems at national level & 7 & 6.1 \\
\hline do not know & 22 & 19.3 \\
\hline Total & 114 & 100.0 \\
\hline
\end{tabular}

Table 4.3.14. Extent of agreement that spraying is done at the same time every year by reason for variation $(n=$ 114)

\begin{tabular}{|l|l|l|l|}
\hline $\begin{array}{l}\text { Extent of agreement that } \\
\text { spraying is done at the same } \\
\text { interval }\end{array}$ & \multicolumn{3}{|l|}{ Reasons for variation in spraying } \\
\cline { 2 - 4 } & $\begin{array}{l}\text { Late arrival of funds/ } \\
\text { logistics/ poor timing/ } \\
\text { planning }\end{array}$ & $\begin{array}{l}\text { Problems at } \\
\text { national level/ do } \\
\text { not know }\end{array}$ & Total \\
\hline Strongly agree/ agree & $27(71 \%)$ & $11(28.9 \%)$ & $38(100 \%)$ \\
\hline Strongly disagree/ disagree & $58(76.3 \%)$ & $18(23.6 \%)$ & $76(100 \%)$ \\
\hline Total & $85(74.5 \%)$ & $29(25.4 \%)$ & $114(100 \%)$ \\
\hline
\end{tabular}

Table 4.4.1. Facilities Checklist

\begin{tabular}{|l|l|l|l|l|}
\hline No. & Item & Present (+) & Absent (-) & Comments \\
\hline 1. & Disposal bay & & $(-)$ & Being constructed \\
\hline 2. & Wash bay & & $(-)$ & Being constructed \\
\hline 3. & Shower & $(+)$ & & Not adequate \\
\hline 4. & Change room & & $(-)$ & \\
\hline 5. & Preparation bay & & $(-)$ & Being constructed \\
\hline
\end{tabular}

Table 4.4.4. Adequacy of wash bay and shower clog $(n=114)$

\begin{tabular}{|l|l|l|}
\hline Level of agreement & Frequency & Percent \\
\hline strongly agree & 4 & 3.5 \\
\hline Agree & 29 & 25.4 \\
\hline Disagree & 50 & 43.9 \\
\hline strongly disagree & 31 & 27.2 \\
\hline Total & 114 & 100.0 \\
\hline
\end{tabular}

Table 4.5.1. Areas of improvements $(n=114)$

\begin{tabular}{|l|l|}
\hline Area of improvement & Frequency \\
\hline 1. Give IEC on importance of IRS and community sensitization & $51(44.7 \%)$ \\
\hline 2. IRS Program to start early around august to October before the rainy starts & $24(28.8 \%)$ \\
\hline 3. Need for adequate funding & $18(15.8 \%)$ \\
\hline $\begin{array}{l}\text { 4. Government to distribute bed nets for those who agree to have their homes } \\
\text { sprayed }\end{array}$ & $7(6.1 \%)$ \\
\hline $\begin{array}{l}\text { 5. Government to put more effort in sensitizing the community such as involving } \\
\text { the church leaders and traditional rulers, councilors and ward chairmen in IRS } \\
\text { programs }\end{array}$ & $4(3.5 \%)$ \\
\hline 6. Government to improve in public partnership & $1(0.8 \%)$ \\
\hline 7. Supervision should improve to counter check with work done in the field & $5(4.3 \%)$ \\
\hline
\end{tabular}




\begin{tabular}{|l|l|}
\hline $\begin{array}{l}\text { 8. To change chemicals like DDT as people complain that it dirtens homes, } \\
\text { instead K-othrine \& Fedona to be used as they kill other vectors. }\end{array}$ & $3(2.6 \%)$ \\
\hline $\begin{array}{l}\text { 9. To stop reducing spray days like this year they reduced to 44 days \& most } \\
\text { houses won't be sprayed as time would not be enough }\end{array}$ & $4(3.5 \%)$ \\
\hline 10. Need to build a shower, changing room \& store room to be expanded & $3(2.6 \%)$ \\
\hline 11. Also improve on payment of spray operators like K100, 000 per day & $5(4.3 \%)$ \\
\hline $\begin{array}{l}\text { 12. Also giving enough milk to neutralize the chemicals as the chemicals are very } \\
\text { strong }\end{array}$ & $1(0.8 \%)$ \\
\hline $\begin{array}{l}\text { 13. No suggestion } \\
\text { 14. Need for management \& spray operators to work together, supervisors to be } \\
\text { involved }\end{array}$ & $10(6.7 \%)$ \\
\hline
\end{tabular}

Table 4.5.2. Possible Solutions

\begin{tabular}{|c|c|}
\hline Solution for the Challenge & Domain \\
\hline $\begin{array}{l}\text { 1. Construction of a wash bay to have a drain where pumps are stored, chemicals } \\
\text { and pumps to be separated } \\
\text { 2. Renovated available infrastructure } \\
\text { 3. Proposed to council management to be given another room for IRS material } \\
\text { storage and to improve ventilation as it is very hot } \\
\text { 4. Partners have come in to improve the wash bay and showers } \\
\text { 5. Extend the store room to cater for all requirements on IRS } \\
\text { 6. Chemicals to be placed on the middle to leave room for air circulation in the } \\
\text { store room } \\
\text { 7. Separate ablution block to be built, build another store room for pumps, have } \\
\text { transport for program officers to ease movements, and to have a separate account } \\
\text { for IRS as it is put in DHMT account. }\end{array}$ & Institutional \\
\hline $\begin{array}{l}\text { 8. IEC to be continuous in the community even before IRS starts } \\
\text { 9. Integrated vector management- Boam or Doom to be sprayed together with the } \\
\text { chemicals } \\
\text { 10. To provide transport for program officers to ease movements, and must have a } \\
\text { separate account for IRS as it is put in DHMT account. } \\
\text { 11. Funding should be done on time from stakeholders, NMCC \& MOH } \\
\text { 12. Need to procure equipment like printers \& photocopiers in place } \\
\text { 13. Tender procedures in Lusaka to be done early so that spraying starts early } \\
\text { 14. Funding to be increased to enable them procure } 2 \text { light vehicles. } 1 \text { for the staff } \\
\text { \& } 1 \text { for the water bulser since there is no horse } \\
\text { 15. Increase community sensitization } \\
\text { 16. Increase number of spray days from } 44 \text { days to } 70 \text { days } \\
\text { 17. If our budget are given or respected the way we have planned } \\
\text { 18. Procure more spray pumps } \\
\text { 19. Need for adequate sensitization to start prior to spraying } \\
\text { 20. Attitude of spray operators to be monitored - spray water instead of chemicals } \\
\text { affecting success of IRS } \\
\text { 21. Changing of supervisors as they over stay } \\
\text { 22. Need for inventory of used \& unused chemicals to match with original supply } \\
\text { after the exercise }\end{array}$ & Operational \\
\hline $\begin{array}{l}\text { 23. Ventilation to be improved in the store room } \\
\text { 24. Construction of a wash bay to have a drain where pumps are stored } \\
\text { 25. chemicals and pumps to be separated }\end{array}$ & Policy \\
\hline
\end{tabular}




\section{Recommendations for improving IRS}

- The study must be duplicated on a larger scale in other geographical areas to enable generalization of results. Also, a study should be done in the community to identify the gaps in IRS and how challenges can be addressed from the community point of view.

- There is need for the districts to have contingency funds from their own funds. Resources should be mobilized from stakeholders as a contribution to maintain continuity of the IRS programme, so that there is no delay in starting of IRS campaign.

- Institutional structures like store room for IRS must be refurbished and where they are not available must be constructed according to the ECZ and WHO standard guideline on Infrastructure for IRS.

- NMCC in conjunction with MOH and ECZ should ensure that the DDT is handled with care without environmental contamination by ensure that wash bay, preparation bay, and shower clog are available in all IRS district to prevent environmental pollution.

- There is need to invest in operational research resulting in malaria development of other types of insecticide and we are building up on this point which was stated in previous research by Korrick et al., (2001); Rogan and Chen (2005) and Fenster et al., 2006).

\section{References}

[1]. Adhanom T, Deressa W, Witten KH, Getachew A \& Seboxa T (2006). Malaria. In: Epidemiology and Ecology of Health and Disease in Ethiopia, 3rd edn (Eds Y Berhane, D Haile-Mariam \& H Kloos) Shama Books, Addis Ababa, pp.556 - 576.

[2]. Bruce-Chatt, L. J. Lessons learned from applied field research activities in Africa during the malaria eradication era. Bulletin of the World Health Organization. 1984. 62 (Suppl.). 19-29.

[3]. Casimiro S (2003). Susceptibility and Resistance to Insecticides among Malaria Vector Mosquitoes in Mozambique. MSc Thesis, University of Natal, South Africa

[4]. Carson, R. (1962). Silent Spring. Boston: Houghton Mifflin

[5]. Chanda E, Masaninga F, Coleman M, Sikaala C, Katebe C, Macdonald M, Baboo K. S, Govere J, \& Manga L. (2008). Integrated Vector management: The Zambian experience. Lusaka, Zambia.

[6]. Chanda E. Coleman M, Govere J, Lindsay S, Fillinger U, Baboo K.S, Kawesha C.E, \& Shinondo C. J. (2003 unpublished). The transmission attributes of peri-urban malaria precedent integrated vector management strategy in Lusaka, Zambia.

[7]. Chapin G, Wasserstrom R (1981). "Agricultural production and malaria resurgence in Central America and India". Nature 293 (5829): 181-5. doi: 10.1038/293181a0. PMID 7278974.Chen A, Rogan WL. Non-malarial infant deaths and DDT use for malaria control. Emerg Infect Dis 2003; 9:960-4.

[9]. CBOH Health management information system (2004). Annual bulletin of health information system, Lusaka Zambia.

[10]. Dempsey P.A. and Dempsey A.D. (2000). Using nursing research process, critical evaluation and utilization. Lippincott Philadelphia

[11]. Gunasekaran K, Sahu, S.S, Jambulingam P. P, Das, P.K (2005). DDT indoor residual spray, still an effective tool to control Anopheles fluviatilis-transmitted Plasmodium falciparum malaria in India. Tropical Medicine \& International Health 10 (2), 160 -168 doi:10.1111/j.1365-3156.2004.01369.x

[12]. Guyatt, H.L., S.K. Corlet, T.P. Robinson, S.A. Ochola, and R.W. Snow. Malaria prevention in highland Kenya: insecticide treated bed nets vs. indoor residual household spraying. Tropical Medicine and International Health. April 2002. vol. 7 no. 4: pp. 298-303.

[13]. Hanson K, Goodman C, Lines J, Meek S, Bradley D. \& Mills A (2004). The economics of malaria control interventions, global forum for health research. Chapter 2, London school of hygiene and tropical medicine.

[14]. Hargreaves K, Koekemoer LL, Brook BD, Hunt RH, Mthembu J \& Coetzee M (2000). Anopheles funestus resistance to pyrethyroid insecticides in South Africa. Medical and Veterinary Entomology 14, $181-189$.

[15]. Health Management Information System (2008) Ndola district health management team, Ndola, Zambia. [16]. Kapindula, David (2006). Indoor Residual spraying ToT and Post Spay Workshop $2^{\text {th }}$ August 2006. Environmental Council of Zambia, Lusaka, Zambia. 
[17]. Kaplan, B. and Maxwell, J.A. 1994). Qualitative Research Methods for Evaluating Computer Information Systems, in Evaluating Health Care Information Systems: Methods and Applications, J.G. Anderson, C.E. Aydin and S.J. Jay (eds.), Sage, Thousand Oaks, CA.

[18]. Krueger R and Casey M. (2000). Focus groups: A practical guide for applied research. New bury Park: Sage.

[19]. Last J. (1998) Dictionary of epidemiology.

[20]. KwaZulu-Natal. South African Medical Journal 88, 1024- 1028.

[21]. MOH / CSO (2006) Zambia national malaria indicator survey, Lusaka, Zambia.

[22]. MOH (2006) Action plan. Actions for scale-up for impact on malaria in Zambia. In support of the National malaria strategic plan 2006-2011. Lusaka, Zambia.

[23]. MOH (2006) Annual Health Statistical Bulletin. Health management Information System. Lusaka, Zambia.

[24]. MOH (2008) National malaria control action plan. Actions for scale up for impact on malaria in Zambia. In support of the national malaria strategic plan 2006-2010

[25]. Musawenkosi L.H, Sharp B, Lengeler C (2004) Historical review of malaria control in southern African with emphasis on the use of IRS. Malaria research program, medical research council, Blackwell publishing Ltd. Durban, South Africa. European journal of tropical medicine and international health volume 9, issue 8, august 2004. ISSN 1360-2276.

[26]. Najera J.A (2001) malaria control: Achievements, problems \& strategies. Parasitologia 43, 1-89.

[27]. National malaria control center (2005) Commitment to rapid scale up for impact, Lusaka, Zambia.

[28]. National malaria strategic plan (2006- 2011), Rapid scale up of malaria control interventions for impact in Zambia, Lusaka, Zambia.

[29]. National malaria control centre (1999) situational analysis of malaria in Zambia, Lusaka, Zambia.

[30]. Newberry K \& Jansen EJ (1986) The common bedbug Cimex lactularius in African huts. Transactions of the Royal Society of Tropical Medicine and Hygiene 80, 653- 658.

[31]. Olliaro, P., Cattani, J. and Wirth, D. (1996) Malaria, the submerged disease. J. Am. Med. Assoc. 275, 230-233.

[32]. Park K. (2007) Park's text book of preventive and social medicine, $19^{\text {th }}$ edition, M/s Bharnasidas Bhanot publishers, India

[33]. ${ }^{1}$ Patton, M.Q. (1987). How to Use Qualitative Methods in Evaluation. Newbury Park, CA: Sage Publications, Inc

[34]. Prof. K.S Baboo (2007) Report on cascade training done from 8/07/07 to 5/08/07 in Kabwe, Kafue, Chongwe \& Lusaka, Zambia.

[35]. Roberts D, Curtis C, Tren R, Sharp B, Shiff C, Bate R. Malaria control and public health. Emerg Infect Dis 2004; 10:1170-1.

[36]. Rogan WJ. The DDT question. Lancet 2000; 356:1189.

[37]. Rogan WJ and Chen A (2005). "Health risks and benefits of bis (4-chlorophenyl) -1, 1, 1trichloroethane (DDT)". Lancet 366 (9487): 763-73.

[38]. Mabaso ML, Sharp B, Lengeler C (2004). "Historical review of malarial control in southern African with emphasis on the use of indoor residual house-spraying". Trop. Med. Int. Health 9 (8): 846-56.Malaria Foundation International (2008) Is DDT still effective and needed in malaria control? Retrieved on 2008-0623

[40]. Malaney P (2003) Micro-Economic Approaches to Evaluating the Burden of Malaria. Working Paper No.99. Center for International Development, Harvard University, USA

[41]. Marianela Castillo-Riquelme, Diane McIntyre, Karen Barnes (2008) Household burden of malaria in South Africa and Mozambique: is there a catastrophic impact? Tropical Medicine \& International Health Volume 13 Issue 1 Page 108-122, January 2008.

[42]. Mnzava AEP, Ntuli VM, Sharp B, Ngxongo S, Mthembu JD \& le Sueur D (1998) House spraying and replastering in

[43]. DDT. Lancet 2005; 366:1771-2.

[44]. Rosenstock L, Cullen M, Bodkin C, Redlich C. Textbook of clinical occupational and environmental medicine. Philadelphia: W.B. Saunders; 1994. 
[45]. Rowe A. K, Steketee R.W, Arnold F, Wardlaw T, Basu S, Bakyaita N, Lama M, Winston C. A, Lynch M, Cibulskis R.E, Shibuya K, Ratcliffe A.A, Nahlen B. L (2007). Viewpoint: Evaluating the impact of malaria control effort on mortality in Sub-Saharan Africa. Tropical Medicine \& International Health

[46]. Volume 12 Issue 12 Page 1524-1539, December 2007

[47]. RTI international (2007) Integrated vector management programmes for malaria vector control. Pragmatic environmental assessment January 2007 (Biscoe et al in RTI international 2007) Cornwallis Road, united states.

[48]. Mark Rowland, Pervaiz Mahmood, Javed Iqbal, Ilona Carneiro, Desmond Chavasse (2000) Indoor residual spraying with alphacypermethrin controls malaria in Pakistan: a community-randomized trial. Tropical Medicine \& International Health 5 (7), 472-481 doi:10.1046/j.1365-3156.2000.00581

[49]. Sachs J \& Malaney P (2002) The economic and social burden of malaria. Nature 415, 680 - 685

[50]. Sadasivaiah, Shobha; Tozan, Yesim \& Breman, Joel G. (2007)

[51]. Sikazwe G.M (2003) A study on malaria control measures among community members in Lusaka Urban District. Lusaka, Zambia (un-published).

[52]. Simpungwe Kakungu Dr. (2007) Ndola district roll back malaria report 2007. Ndola, Zambia.

[53]. Sipilanyambe N \& Nalishebo (2005) An evaluation of the social economic factors associated with malaria in Zambia. Lusaka, Zambia.

[54]. Torres-Arreola L, Berkowitz G, Torres-Sánchez L, López-Cervantes M, Cebrián ME, Uribe M, et al. Preterm birth in relation to maternal organochlorine serum levels. Ann Epidemiol 2003; 13:158-62.

[55]. The laws of Zambia (1964) CAP 557 mosquito extermination act.

[56]. Tren \& Bates (2004) "South Africa's war on malaria" policy analysis number 513, March 25, 2004, Cato institute, Washington DC.

[57]. United Nations Children's Fund (2003) Africa malaria report.

[58]. http://rbm.who.int/amd2003 (accessed on 02/Apr/2007

[59]. US Department of State (2006) U.S. Senator Does a "Slam Dunk" for Africa Malaria Day.

[60]. Waissmann W. Endocrinopatologia associada ao trabalho. In: Mendes R, organizador. Patologia do trabalho. São Paulo: Editora Atheneu; 2003. p. 1093-138.

[61]. Wakgari Deressa, Damen Hailemariam, Ahmed Ali (2007) Economic costs of epidemic malaria to households in rural Ethiopia Tropical Medicine\& International Health 12 (10), 1148-1156 doi:10.1111/j.13653156.2007.01901.x

[62]. World Health Organization (1993) A Global Strategy for Malaria. WHO, Geneva.

[63]. World Health Organization (1994) Wkly. Epidemiol. Rec. 69, 309â€“316.

[64]. WHO (1998) Test procedures for insecticide resistance monitoring in malaria vectors, bio-efficacy and persistence of insecticides on treated surfaces. In report of the WHO informal consultation, Geneva. 28$30^{\text {th }}$ September 1998.

[65]. WHO (2000a) WHO Expert Committee on Malaria, 20th report. Technical Report Series No. 892, WHO, Geneva.

[66]. WHO (2000b) The Abuja Declaration on Roll Back Malaria in Africa by the African Heads of States and Governments, 25th April 2000, Abuja, Nigeria. Statement prepared by RBM, WHO, Geneva, April 2000.

[67]. WHO (2004) Zambia malaria foundation indoor residual spraying. Lusaka. Zambia

[68]. WHO (2006) Indoor Residual Spraying. Use of indoor residual spraying for scaling up global malaria control and elimination. WHO/HTM/MAL/2006.1112.

[69]. WHO (2006) WHO gives indoor use of DDT a clean bill of health for controlling malaria [70]. Worrall E, Rietveld A \& Dellacollette C (2004) The burden of malaria epidemics and cost-effectiveness of interventions in epidemic situations in Africa. American Journal of Tropical Medicine and Hygiene 71(suppl.2), $136-140$. 